\title{
EXPERIÊNCIA DA UNICENTRO NO PROJETO RONDON EM IRITUIA/PA: UMA LIÇÃO DE VIDA E CIDADANIA
}

\author{
Ana Paula Perardt Farias \\ Universidade Federal do Paraná \\ ana.perardt@hotmail.com
}

\author{
Franciani Fernandes Galvão \\ Universidade Estadual do Centro-Oeste do Paraná \\ francianigalvao@gmail.com \\ Edson Santos Silva \\ Universidade Estadual do Centro-Oeste do Paraná \\ jeremoabo21@gmail.com
}

\section{Resumo}

Esse artigo relata a experiência da extensão universitária no desenvolvimento das atividades dos estudantes universitários, idealizada na cidade de Irituia - Pará, em Julho de 2013, na Operação Forte do Presépio do Projeto Rondon. A proposta executada foi construída por alunos da Universidade Estadual do Centro Oeste - Unicentro no Paraná e se baseou no conjunto B, que aborda os campos de Comunicação, Tecnologia e Produção, Meio Ambiente e Trabalho, cujo objetivo foi: Relatar e compartilhar as experiências obtidas pela equipe da Unicentro no Projeto Rondon. O desenvolvimento das atividades consistiu na prática de ações participativas, que buscaram a formação e sensibilização de responsabilidade social e coletiva, em prol da cidadania. Essa experiência extensionista permitiu a melhoria de todos os envolvidos, pois ampliou a visão e o conhecimento do universitário diante da realidade da comunidade, rompendo as barreiras do conhecimento e proporcionando a busca por estratégias e soluções para o trabalho contínuo, e, para a melhoria da qualidade de vida do município.

Palavras-chave: Projeto Rondon. Experiência de vida. Cidadania. Unicentro.

\section{EXPERIENCE OF THE UNICENTRO IN THE RONDON PROJECT IN IRITUIA/PA: A LESSON OF LIFE AND CITIZENSHIP}

\begin{abstract}
This article reports a university extension experience in the students developing activities in the city of Irituia - Pará, in July 2013, in the Rondon Project Forte do Presépio Operation. The proposal of activities made was built by students of the Centro-Oeste State University - Unicentro in Paraná (Brasil) and was based on the set B, including activities such as communication, technology and production, environment and work, the objective was: Report and sharing experiences obtained by the Unicentro's team in the Rondon Project. The development of activities consisted in the practice of participative actions, which sought social and collective responsibility for citizenship. This extension experience allowed the growing of everyone involved, by expanding the vision and knowledge of the student to the community reality, breaking the barriers of knowledge and providing the search for strategies and solutions to the ongoing work, and to improve the quality of municipal life.
\end{abstract}

Keywords: Rondon Project. Life experience. Citizenship. Unicentro.

\section{EXPERIENCIA DE LA UNICENTRO EN EL PROYECTO RONDON EM IRITUIA/PA: UNA LECCIÓN DE VIDA Y CIUDADANIA}

\section{Resumen}

Este artículo da cuenta de la experiencia de extensión universitaria en el desarrollo de las actividades de los estudiantes universitarios, desarrollada en la ciudad de Irituia - Pará en julio de 2013, en el Proyecto Forte do Presépio de Operación Rondon. La propuesta ejecutada fue construida por estudiantes de la Universidad Estadual del Centro-Oeste - Unicentro en Paraná (Brasil) y se basó en el conjunto B, que abarca los campos de la comunicación, Tecnología y Producción, MedioAmbiente y Trabajo, cuyo objetivo fue: Informar y compartir experiencias obtenidas por el equipo de Unicentro en el Proyecto Rondon. El desarrollo de las actividades fue la práctica de forma participativa, que buscó la formación y la conciencia de la responsabilidad social y colectiva, a favor de la ciudadanía. Esta extensión experiencia permitió la mejora de todos los involucrados, amplió la visión y el conocimiento de la universidad ante la comunidad de la realidad, rompiendo las barreras del conocimiento y la disponibilidad para la búsqueda de estrategias y soluciones a los trabajos en curso, y para mejorar la calidad de vida en el municipio.

Palabras-clave: Proyecto Rondon. Experiencia de vida. Ciudadania. Unicentro 


\section{INTRODUÇÃO}

A extensão universitária é uma forma de interação que deve existir entre a universidade e a comunidade na qual ela está inserida, fazendo com que haja uma ligação contínua entre a universidade e a sociedade. Funciona como uma devolutiva, pois a universidade leva conhecimentos ou auxílio à comunidade e recebe dela retornos positivos, como o conhecimento da comunidade local, suas reais necessidades, anseios e aspirações, tornando-se mais produtiva a experiência do universitário para sua formação cidadã (NUNES; SILVA, 2011).

Segundo o Plano Nacional de Extensão, elaborado pelo Fórum de Pró-Reitores de Extensão das Universidades Públicas Brasileiras e pela Secretaria do Ensino Superior do Ministério da Educação e do Desporto, a extensão universitária é o processo educativo, cultural e científico que profere o ensino e a pesquisa de forma indissociável e viabiliza a relação transformadora entre universidade e sociedade (NUNES; SILVA, 2011).

O fortalecimento da relação universidade e sociedade prioriza a superação das condições de desigualdades e exclusão que ainda existem, por meio de projetos sociais, a universidade compartilha seu conhecimento e disponibiliza seus serviços, exercendo seu papel de cidadão e principalmente de responsabilidade social, ou mesmo sua missão: o compromisso com a melhoria da qualidade de vida de seus cidadãos. (NUNES; SILVA, 2011).

Diante disso, a extensão universitária tem como objetivo principal articular o conhecimento construído na universidade com a realidade e as necessidades da população, aliando a teoria com a prática e contribuindo com a formação de profissionais mais sensíveis e capacitados com às necessidades sociais (HENNINGTON, 2005).

Um grande exemplo de projeto de extensão universitária é o Projeto Rondon, considerado o maior projeto de extensão do Brasil e busca a integração social, além de envolver a participação voluntária de estudantes universitários, na busca de soluções que contribuam para o desenvolvimento sustentável de comunidades carentes e para a ampliação e o bem-estar da população, assim como o retorno de uma experiência significativa para a vida de cada estudante. É coordenado pelo Ministério da Defesa e que tem parcerias com diversos Ministérios, além do apoio das Forças Armadas, que proporcionam o suporte logístico e a segurança necessária às operações. Conta, ainda, com a colaboração dos Governos Estaduais, das Prefeituras Municipais e de Empresas socialmente responsáveis (PROJETO RONDON, 2015).

O projeto envolve atividades voluntárias de universitários, e busca aproximar esses estudantes com a realidade do país, além de contribuir para o desenvolvimento de comunidades carentes. A extensão também permite aos membros das Instituições de Ensino Superior (IES) a 
oportunidade de conhecerem a sociedade com mais proximidade e perceberem suas reais necessidades, beneficiando a comunidade para seu desenvolvimento e a garantia dos valores de igualdade de direitos e participação, dando possibilidades tanto para a universidade quanto para a comunidade, além de dar voz e valores para as pessoas que vivem ali.

A participação no Projeto Rondon sempre foi um objetivo a ser alcançado na vida dos universitários da Unicentro que se envolveram na Operação Forte do Presépio no Pará em Julho de 2013. Foi por meio do interesse de duas acadêmicas do curso de turismo, juntamente com a sua professora de marketing que desenvolveram o trabalho. Nesse momento, surgiu a oportunidade de submeter o projeto com a participação de mais seis acadêmicos de outros cursos e mais uma pessoa encarregada de ser vice coordenador, que tornaria realidade o sonho de muitos jovens, muitas emoções, ansiedade, curiosidade, responsabilidade e um grande desafio para esses universitários.

Foi então com o intuito de vivenciar o Projeto Rondon que nos constituímos em uma equipe, composta por oito estudantes e dois professores, apresentando uma formação interdisciplinar com integrantes dos cursos de Turismo, Geografia, Engenharia Florestal, Engenharia Ambiental e Administração. Essa equipe representou a Unicentro, na Operação Forte do Presépio que foi realizada nos dias 06 a 22 de Julho de 2013 abrangendo o conjunto B de ações - Comunicação, Meio Ambiente, Tecnologia e Produção e Trabalho com objetivo de desenvolver as atividades no município de Irituia - Pará.

Após a constituição da equipe, elaboramos a proposta e enviamos ao Ministério da Defesa. O Ministério da Defesa escolheu o município de atuação conforme necessidade local e aceitação da prefeitura. O município selecionado pelo Ministério da Defesa a ser beneficiado pelo projeto Rondon foi um pequeno local na região nordeste do estado do Pará chamado Irituia, com uma população total de 31.644 habitantes (IBGE, 2014).

Após o conhecimento da cidade que receberia a operação, foi realizada a viagem precursora pelo professor coordenador da equipe com a finalidade de adequar as propostas feitas à realidade municipal. Com o retorno do coordenador da viagem precursora, realizamos várias reuniões, testes para as oficinas que iríamos fazer, e atividades para nos prepararmos para as ações no município, bem como o que iríamos levar de materiais para a realização das atividades.

Buscou-se, no presente trabalho, detalhar e ressaltar o trabalho e as atividades desenvolvidas pelos acadêmicos da Unicentro, expondo o pouco do conhecimento que se adquiriu em sala de aula para a comunidade. Para isso, tem-se como objetivo: Relatar e compartilhar as experiências obtidas com a equipe da Unicentro no Projeto Rondon - Operação Forte do Presépio na cidade de Irituia - Pará. 


\section{MATERIAIS E MÉTODOS}

No início do ano de 2013 o Ministério da Defesa lançou o convite para a seleção de universidades a participarem da Operação Forte do Presépio do Projeto Rondon a ser desenvolvida entre os dias 06 de julho a 22 de julho de 2013, em municípios dos Estados do Pará e Maranhão. Por meio desse convite, as universidades interessadas encaminharam seus projetos, oportunizando a participação de docentes e discentes em atividades de extensão. Frente a essa oportunidade, alunos da Universidade Estadual do Centro-Oeste do Paraná - Unicentro mostraram interesse e construíram uma proposta que se baseou no conjunto B, que aborda as áreas de Comunicação, Meio Ambiente, Tecnologia e Produção e Trabalho. Diante da equipe interdisciplinar do projeto, a mesma foi constituída por estudantes de diversas áreas, duas alunas do curso de Turismo, uma aluna e um aluno de Geografia, duas alunas de Engenharia Florestal, um aluno de Engenharia Ambiental e uma de Administração. Os professores responsáveis pela orientação da equipe tinham formação na área de Administração e Marketing e Letras.

A proposta foi aprovada e teve como designação pelo Ministério da Defesa a cidade de Irituia - Pará, para nossa atuação. Por conseguinte, a professora coordenadora realizou a viagem precursora, para melhor conhecimento, sobre o Projeto Rondon, bem como a visita, no período de uma semana, ao município de Irituia, para conhecimento prévio à operação e repasse para a equipe sobre as informações e peculiaridades do local, que foram úteis principalmente para adaptações e mudanças em nossa proposta inicial.

No dia 06 de Julho de 2013, a equipe partiu para Belém - PA. Na capital, aconteceu a concentração de todas as equipes que iriam atuar na Operação Forte do Presépio. Fomos distribuídos no Centro de Instrução Almirante Braz (CIABA) e no $2^{\circ}$ Batalhão de Infantaria de Selva (BIS) da Marinha do Brasil, e, pela noite, tivemos uma recepção calorosa com um jantar de comidas típicas e danças locais. No mesmo dia fomos prestigiados com uma bela solenidade, com o desfile da marinha e discurso de boas vindas. A partir de então, fomos para a Universidade Federal do Pará (UFPA) no qual foi feita apresentação sobre aspectos culturais, econômicos, sociais, entre outros, referentes ao estado do Pará e também sobre a estrutura do Projeto Rondon, bem como saber todos os detalhes da operação que iria se iniciar.

No dia 07 de Julho, foi o momento de embarque de nossa equipe para Irituia, com ônibus disponibilizado pelo Projeto Rondon. No município, atuaram duas equipes: os integrantes da Universidade Estadual do Centro-Oeste - Unicentro e os integrantes da equipe que representava a Universidade Tiradentes - Unit de Aracaju, Sergipe. As duas equipes trabalharam com muito 
entrosamento. Buscamos uma interação com a comunidade e tomamos como base a metodologia participativa em todas as atividades realizadas, pois é uma forma inclusiva, de valorização dos sujeitos marcando a participação ativa de todos os envolvidos, valorizando o saber local que se inter-relaciona ao saber científico (ANDRADE; SOUZA; RAMOS, 2005 apud BULHÕES et al, 2010). Para a realização das atividades, resolvemos aplicar as oficinas a seguir, distribuídas em áreas distintas:

\section{Comunicação}

- Oficina I: Produção fotográfica digital

- Oficina II: Comunicação gráfica

- Oficina III: Elaboração de material informativo - jornal, cartilha, folder, cartaz e informativo

- Oficina IV: Comunicação virtual (mídias sociais)

- Oficina V: Comunicação Oral (curso de oratória)

\section{Meio Ambiente}

- Oficina I: Saneamento básico

- Oficina II: Coleta e seleção de lixo reciclável por meio de caminhada ecológica

- Oficina III: Técnicas de artesanato com produtos recicláveis

- Oficina IV: Geração de renda com atividades não madeireiras

- Oficina V: Preservação dos recursos naturais/ mananciais

- Oficina VI: Promoção da conservação ambiental

- Oficina VII: Saneamento rural

\section{Tecnologia e Produção}

- Oficina I: Práticas de estabelecimento e manejo da produção de Feijão, Mandioca e Milho (cultura temporária) com vistas ao aumento da produtividade e da relação custo benefício

- Oficina II: Sobre extração e manejo do mel

- Oficina III: Sobre extração e manejo do açaí

- Oficina IV: Sobre extração e manejo da lenha e carvão vegetal

- Oficina V: Principais práticas de estabelecimento e manejo das espécies forrageiras indicadas para cultivo na região, bem como a importância da análise de solo, correção de acidez e fertilidade 
- Oficina VI: Práticas de higiene de ordenha visando diminuição e controle de mastite e qualidade do leite

- Oficina VII: Visitas em propriedades com discussão sobre o manejo empregado, sugestões de manejo e prática de coleta de solo para análise

- Oficina VIII: Produção de queijo e doce de leite visando agregar valor ao leite

- Oficina IX: Industrialização de frutas tropicais: técnicas de produção de doces, compotas e geleias de banana, pimenta, laranja e, principais frutas produzidas na região (e outras frutas designadas pela população)

- Oficina X: Esterilização de vidro e potes

- Oficina XI: Estudo de mercado para venda dos produtos

\section{Trabalho}

- Oficina I: Empreendedorismo: conceito, tipos, características, espírito empreendedor, novos modelos, importância para Irituia, aplicações práticas, casos de sucesso

- Oficina II: Planejamento empresarial: da abertura à venda final

- Oficina III: Criação e implantação de feira agroecológica

- Oficina IV: Linhas de crédito voltadas ao micro e pequeno empreendedor: aplicações, relevâncias, valores, atualidades

- Oficina V: Controles financeiros básicos

- Oficina VI: Cooperativismo e Associativismo

- Oficina VII: Projetos: definição, características, modelos de projetos, projetos públicos e privados

- Oficina VIII: Capacitação de gestores públicos: padronização na capacitação da gestão pública

- Oficina IX: Turismo: capacitando os munícipes para identificação de potencial turístico local e comércio de bens e serviços turísticos

Cada oficina realizada era composta de, no mínimo, dois a quatro rondonistas, distribuídos de acordo com o planejamento. Na parte da noite, após a realização das oficinas do dia, eram feitas reuniões com toda a equipe com o objetivo de aprimorar o desenvolvimento e a melhoria das próximas oficinas e atividades, bem como observações dos pontos positivos e negativos. 
A execução das atividades foi realizada na cidade de Irituia na Escola Francisco Nunes e nos distritos do interior, comunidades de: Araraquara, Itabocal, entre outras. Desempenhamos, além das oficinas, limpeza da praça e atividades recreativas, juntamente com a equipe do conjunto A, também houve participação dos rondonistas no XXIX Festival da Cultura Irituiense que acontece todo ano no município.

Implementamos também uma oficina de práticas de compotas, geleias e doces, juntamente com um grupo de mulheres da cidade, fizemos compota de laranja, geleia de pimenta e doce de banana. No decorrer das atividades, surgiu a necessidade de se trabalhar com algumas oficinas específicas que não estavam no cronograma, principalmente nas comunidades do interior do município, por exemplo, o cultivo e o manejo do açaí, da mandioca, entre outros.

Contamos com o apoio dos órgãos públicos, na divulgação em rádio do município e no boca a boca pelos rondonistas na rua, convidando os Irituienses a participarem das atividades do Projeto Rondon. Conseguimos fazer um amplo trabalho e envolver também, funcionários públicos (prefeitura, secretaria da agricultura e abastecimento, secretaria do meio ambiente), líderes comunitários, Emater (referência em qualidade e extensão rural), e comunidade em geral nas atividades.

No término das atividades no município, fomos muitas vezes homenageados pelo prefeito e as demais pessoas envolvidas que trabalharam conosco nesta empreitada, no último dia na cidade de Irituia, fizemos um jantar típico com a gastronomia típica de Irati no Paraná: Pierogue, um prato típico polonês, e muita música, principalmente o carimbó (dança típica do Pará) para homenagear as pessoas que foram tão queridas e atenciosas conosco durante os quinze dias que passamos em Irituia.

Por fim, no dia 21 de Julho, pela manhã, retornamos a capital Belém, e pela tarde, realizou-se o momento da Solenidade de Encerramento, com distribuição de troféus para as IES e socialização das atividades e experiências desenvolvidas. Apresentamos junto com o conjunto A da UNIT (Universidade Tiradentes) de Aracaju - Sergipe, nossas músicas que fizemos para a cidade de Irituia e para o Projeto Rondon que estava na cidade. Logo após, o coordenador geral encerrou com um discurso geral sobre a Operação Forte do Presépio e como o jovem universitário enfrentou as adversidades das realidades brasileiras. $\mathrm{Na}$ parte da noite, aconteceu a confraternização de encerramento, com um jantar dançante, e, logo após foi o momento de despedida das equipes, o que foi triste, pois formamos uma grande equipe com o Conjunto $\mathrm{A}$, onde se iniciou uma grande amizade por ambas as equipes. Na manhã do dia seguinte, dia 22 de janeiro, cada equipe partiu rumo às suas cidades de origem, Irati no Paraná com a equipe da Unicentro e Aracaju em Sergipe com a equipe da Unit. 


\section{RESULTADOS E ANÁLISES}

Durante os quinze dias que permanecemos em Irituia no Pará, obtivemos êxito nas atividades que desenvolvemos com muitos pontos positivos, mas negativos também. Conseguimos uma interação grande e alcançamos um diálogo satisfatório e gratificante entre os universitários e a comunidade para o desenvolvimento das oficinas e atividades do projeto na cidade. Houve muitos espaços e colocamos a população diante de discussões positivas a respeito dos temas que estávamos trabalhando na cidade, no qual, foi muito válido, pois assim, conseguimos levar o pouco do nosso conhecimento para a prática e a realidade daquela comunidade.

Além disso, também dialogamos com as autoridades locais, secretários do meio ambiente, da agricultura, do trabalho, bem como professores, funcionários públicos e líderes comunitários. Conseguimos uma ótima participação das pessoas em assuntos importantes para o município de Irituia, como a geração de renda com atividades não madeireiras, usando principalmente plantas medicinais nativas, com foco na participação das mulheres de Irituia. Também a promoção da conservação ambiental, visto que o município tem uma extensa área de florestas e mananciais. Além de oficinas como empreendedorismo que foi sucesso, e também da possibilidade de se criar uma feira agroecológica, mostrando o melhor que o município de Irituia produz: suas frutas típicas, verduras, legumes, artesanato, entre outros.

Com relação às oficinas, à área de meio ambiente, rendeu ótimos resultados. Uma das oficinas mais importantes que ofertamos foi a de saneamento básico, visto que a cidade não possui água potável, por isso, ressaltamos a importância da qualidade da água para os moradores e, principalmente, para as crianças que podem adquirir várias doenças por meio dela. Além disso, conseguimos mostrar vários exemplos de como eles podem purificar a água utilizando materiais "baratos" como garrafas pets. As oficinas relativas ao meio ambiente proporcionaram uma interação grande entre a comunidade e os rondonistas, pois muitos a viam como inspiração para continuar o trabalho, visto que era necessário melhorar o saneamento básico tanto da cidade como do meio rural e, também, como eles poderiam preservar os mananciais e proteger melhor o solo.

Ressalta-se que um dos momentos mais marcantes de todo o Projeto Rondon na cidade de Irituia foi a interação e a organização dos conjuntos A e B para um projeto a parte, chamado "Irituiação" em uma comunidade do interior do município, denominada Itabocal, onde os acadêmicos da Unicentro e os da Unit desenvolveram atividades de revitalização de uma praça pública. A praça estava mal cuidada, e mesmo assim, a comunidade se prontificou e ajudou a 
realizar um ótimo trabalho em equipe. O conjunto A ficou responsável pela cultura, educação e entretenimento para exercer atividades com as crianças, oficinas de como fazer bolacha, também construiram balanços e pintaram com cores vivas, e, colocaram nas árvores para a alegria das crianças que estavam se divertindo com as brincadeiras, e com ajuda da própria comunidade que estava se empenhando junto com os rondonistas nesta missão. Assim, o conjunto B ficou responsável pela limpeza da praça, tiramos todo o lixo, recolhemos as folhas das árvores, pegamos inchadas e limpamos o terreno da praça, deixamos o lugar bem acessível e limpo para criar um espaço sociável para aquela comunidade, e mais bonito e agradável para as crianças e seus pais usufruírem para a recreação. Esta foi uma ação que deve ser lembrada, ver todos unidos, cada um ajudando como pôde.

As atividades desenvolvidas nas comunidades do interior foram interessantes, pois fizemos oficinas sobre as principais práticas de manejo, indicadas para o cultivo na região, bem como as visitas em propriedades com sugestões de plantio e melhor prática do solo, além de como podem trabalhar com os produtos da região como mandioca, açaí, mel e frutas da região.

Estas oficinas no interior do município foram extremamente importantes para refletirmos sobre o trabalho desenvolvido, imprevistos acontecem e algumas vezes, em certas oficinas, chegou a faltar energia, ou alguém da equipe esqueceu algum cabo para ligar o data-show (aparelho multimídia), ou tínhamos preparado uma oficina, mas ela não se adequou com o que a comunidade precisava no momento, isso fez com que chegássemos todo dia em nosso alojamento na parte da noite para fazer reunião com todo o conjunto B da Unicentro, sempre após a janta, para repensarmos, estudarmos bem o que iríamos passar nas oficinas, e analisarmos todos os pontos positivos e negativos de cada oficina durante o dia. Esse planejamento foi muito importante para nós rondonistas e também para os professores coordenadores do conjunto $\mathrm{B}$, avaliar bem cada atividade, cada decisão tomada, e o principal, em equipe, todos tinham voz e o direito de falar, e fez com que nossa equipe aprendesse com as falhas e os acertos, e isso nos fez crescer, principalmente como cidadão para melhorarmos nosso trabalho.

Também foram realizadas oficinas para a fabricação e venda de queijo e doce de leite em comunidades do interior e oficina de industrialização de frutas tropicais e técnicas de produção de doces, compotas e geleias com os produtos típicos da região. Foram convidadas para participar as mulheres do município e as merendeiras dos colégios de Irituia, que aprenderam algo novo e poderão repassar esse conhecimento..

Logo, percebeu-se por meio dos relatos dos participantes das oficinas e comunidade em geral, que o momento estava sendo proveitoso e realmente rico para estas pessoas, pois era a 
segunda vez que o Projeto Rondon estava na cidade de Irituia e muitos participaram na primeira vez que os rondonistas chegaram, e também conosco.

Durante esse processo, vale ressaltar em como é válida a experiência da indissociabilidade nas atividades de ensino, pesquisa e extensão e como é fundamental no processo do acadêmico na universidade. A relação entre os três pilares na universidade, quando bem articulados, leva a mudanças significativas nos processos de ensino e de aprendizagem, fundamentando didática e pedagogicamente a formação profissional, pois estudantes e professores constituem-se em sujeitos do ato de aprender, de ensinar e de formar profissionais e cidadãos. A pesquisa e a extensão, em interação com o ensino, com a universidade e a sociedade, possibilitam operacionalizar a relação entre a teoria e a prática, a democratização do saber acadêmico e o retorno desse saber à universidade (DIAS, 2009).

\section{CONSIDERAÇÕES FINAIS}

Durante as atividades do projeto surgiram algumas dificuldades, como falta de espaços, planejamento e organização; mas a equipe conseguiu superar os obstáculos. Também readaptamos algumas oficinas e estudamos antes de passar o conteúdo, principalmente o uso da linguagem conforme a percepção e entendimento do público-alvo. Essas situações aumentaram nosso senso de percepção, e fez com que nos adaptássemos para passar o nosso melhor àquela comunidade, fazendo com que estimulássemos a criatividade, empatia pelo outro, melhorando nossa capacidade de construção e de cidadão.

O município de Irituia contribuiu positivamente ao longo de todo o projeto. Houve um grande número de pessoas presentes nas oficinas, principalmente as realizadas no interior. Além disso, percebemos a participação ativa da população sobre os assuntos que mereciam atenção, muitos se envolveram na organização e execução das atividades, o que foi de grande valia para nós rondonistas. Aprendemos muito com os relatos de experiência da comunidade em geral, fazendo com que refletíssemos, além de acharmos possibilidades para melhorar o dia a dia daquelas pessoas, e, por meio da fala e demonstrações públicas de carinho e cordialidade, a cidade expressou ainda, agradecimentos pelo momento de partilha, de valorização de suas contribuições e reconhecendo que são capazes de lutar pelos seus objetivos e projetos de vida.

A relação entre os rondonistas e o município de Irituia foi única, conhecemos belos lugares, pessoas incríveis, andamos de barco pelo Rio Irituia, conhecemos figuras ilustres da cidade, experimentamos a famosa gastronomia paraense e irituiense, aprendemos a dançar 
carimbó (dança típica do Pará), conhecemos muitas moradias e artesanato local, sensibilizamos Irituia e aprendemos muito mais com eles, do que eles conosco, fizemos muitas amizades, rimos e choramos, e um pedaçinho de nós ficou no Pará e o Pará sempre ficará marcado em nossas vidas.

O Projeto Rondon é uma oportunidade única na vida de qualquer universitário e um privilégio para quem o recebe em seu município. Seguramente os municípios que recebem o Projeto Rondon estão hoje diferentes do que eram antes de compartilhar experiências com as universidades. Além disso, os inúmeros benefícios são para as universidades, pois os alunos aprendem com a diferença, e, principalmente a trabalhar em equipe, estabelecendo contato direto com comunidades que vivem uma cultura e uma realidade diferente do habitual, possibilitando a melhoria na formação cidadã do acadêmico e do futuro profissional.

O Projeto Rondon fortalece os três pilares na universidade: ensino, pesquisa e extensão, e faz com que o professor e aluno se enriquecem nesse processo, o professor, ao integrar seu ensino à pesquisa e à extensão, mantém-se atualizado e conectado com as transformações mais recentes que o conhecimento científico provoca ou mesmo sofre na sua relação com a sociedade, além de formar novos pesquisadores, críticos e comprometidos com a intervenção social e a solidariedade. Por isso, quanto mais integradas estiverem as ações de ensino, pesquisa e extensão, mais integralmente se estará formando o profissional para o mundo do trabalho (MOITA; ANDRADE, 2009).

A experiência extensionista do maior projeto de extensão do país nos permitiu romper as barreiras e obstáculos do conhecimento e oportunizou a busca de soluções precisas, para que o processo seja contínuo e duradouro, e, para que a semente que plantamos na cidade de Irituia com o Projeto Rondon se mantenha viva na memória das pessoas que vivem ali.

\section{REFERÊNCIAS}

ANDRADE, Horasa. Maria. Lima. SOUZA, Robson. Campelo. RAMOS, Elisangela. Moura. Metodologia Participativa como ferramenta e estratégia utilizada pela INCUBACOOP para a inclusão de grupos populares em Recife-PE. Programa incubadora tecnológica de cooperativas populares e empreendimentos solidários Universidade Federal do Pará, 2005. Disponível em: <http://www.cultura.ufpa.br/itcpes/documentos/metodologia_participativa_incubaccop.pdf > Acesso em 30. Jul. 2015.

BRASIL. Ministério da Defesa. Projeto Rondon, 2015. Disponível em <https://www.projetorondon.pagina-oficial.com/portal/> Acesso em 30. Jul. 2015. 
BULHÕES, Alcides. Emanoel. Espindola, et al. Relato de uma experiência de vida: comunidade e rondonistas integrando saberes. Extensio: Revista Eletrônica de Extensão, ISSN 1807-0221 Florianópolis, Ano 7, n. 10, p. 158-172, 2010.

DIAS, Ana Maria Iorio. Discutindo caminhos para a indissociabilidade entre ensino, pesquisa e extensão. Revista Brasileira de Docência, Ensino e Pesquisa em Educação Física. v. 1, n. 1, p. 37-52. Agosto/2009.

HENNINGTON, Élida Azevedo. Acolhimento como prática interdisciplinar num programa de extensão universitária. Caderno de Saúde Pública, Rio de Janeiro, 21(1): 256-265, jan-fev, 2005.

IBGE. Instituto Brasileiro de Geografia e Estatística - Cidades. Disponível em:

$<$ http://cidades.ibge.gov.br/xtras/perfil.php?codmun=150350> Acesso em 30. Jul. 2015.

NUNES, Ana Lucia de Paula Ferreira; SILVA, Maria Batista da Cruz. A extensão universitária no ensino superior e a sociedade. Revista Mal-Estar e Sociedade, Ano IV, n. 7, Barbacena, Julho/Dezembro, 2011. p. 119- 1

MOITA, Filomena Maria Gonçalves da Silva Cordeiro; ANDRADE, Fernando Cézar Bezerra. Ensino-Pesquisa-Extensão : um exercício de indissociabilidade na pós-graduação. Revista Brasileira de Educação , v. 14, n. 41, Maio/Agosto, 20 